\title{
Effect of High Blood Cortisol Concentration on the Spectroscopically Determined Secondary Structure of Proteins and Lipid Balance on the Example of Elite Women Volleyball Players
}

Joanna Depciuch ( $\square$ joanna.depciuch@ifj.edu.pl )

Institute of Nuclear Physics Polish Academy of Sciences

Wojciech Czarny

Rzeszów University

Wojciech Szuszkiewicz

Rzeszów University

Adam Reich

Rzeszów University

Bartosz Klebowski

Institute of Nuclear Physics Polish Academy of Sciences

Wojciech Bajorek

Rzeszów University

Artur Płonka

Rzeszów University

Iwona Łuszczewska-Sierakowska

Medical University of Lublin

Jozef Cebulski

Rzeszów University

Paweł Król

Rzeszów University

\section{Research Article}

Keywords: cortisol concentration, stress level, FTIR, Raman spectroscopy, phospholipids, proteins, amide I, sport, volleyball.

Posted Date: February 24th, 2021

DOl: https://doi.org/10.21203/rs.3.rs-228476/v1 
License: (c) (i) This work is licensed under a Creative Commons Attribution 4.0 International License. Read Full License 


\section{Abstract}

Cortisol is a stress hormone plays a crucial role in the balance between phospholipids and lipids level. In consequence, it affects the secondary structure of proteins. Currently cortisol concentration in plasma is determined by biochemical analysis. A new, optical method to estimate stress level is proposed in this work. Infrared and Raman spectroscopies were used to determine quantitative and qualitative changes in the lipids and proteins fraction in function of cortisol concentration in 49 samples of plasma collected from volleyball players at various stages of preparation for the competition. With the cortisol level increase, a decrease of structures related to $\mathrm{PO}^{2-}$ phospholipids groups and amides III, II and I bonds was noticed in the transmission spectra. Changes in the secondary structure of protein were indicated as a frequency shift of a-helix and $\beta$-sheet vibrations observed in Raman spectra and second derivative of transmission spectra. Pearson correlation test presented positive correlations between phospholipids and proteins level and between cortisol concentration and phospholipids in transmittance spectra. Negative correlations between cortisol concentration and proteins and phospholipids level was observed in the Raman spectra. Both optical techniques are considered to become effective tools for estimating the concentration of cortisol in the plasma.

\section{Introduction}

Both control as well as precise determination of the stress level are of significant importance for a wide range of various professions. They are essential for the appropriately planned and precisely conducted training for the professional athletes as well as for firemen, selected types of military troops, police departments etc. Without a doubt, the level of stress can influence a quality as well as an efficiency of professional activity. While for athletes the sports competitions are a key time for their performance, for other highly specialized professionals, such as medical staff involved in life-saving activities, stress is present every day. Cortisol is one of the stress hormones, which belongs to the hormones from glucocorticoids group. This hormone is responsible for preparing the body to physical and mental stress. Oxidative stress resulting from physical exertion in elite athletes can take various forms ${ }^{1}$. Depending on the level of physical effort or competition, changes in the concentration of hormones in the body may also vary, but they always occur in female volleyball players' bodies ${ }^{2-4}$. The higher the level of sports advancement of the female players, the higher the changes in cortisol levels can be observed, which proves that the body responds to the level of training load ${ }^{5}$. The very precise mechanism of cortisol's activity is not fully explained because at the cellular level it has got an anabolic character (stabilization of lysosomal membranes and reduction of the activity of protein-digesting enzymes), while in relation to muscles, it possesses a catabolic character (it stimulates, inter alia, myostatin synthesis) ${ }^{6-7}$. For this purpose, it affects the metabolism of proteins, carbohydrates and fats ${ }^{8}$.

The long-term stress first results in a hyperactivation of the sympathetic nervous system. As a next step, the level of the corticotropin releasing hormone $(\mathrm{CRH})$ increases, followed by adrenocorticotropic hormone (ACTH) secretion. The secretion of ACTH caused secretion of stress hormone such as cortisol 
from the adrenal cortex ${ }^{9}$. The high level of cortisol affects the lipid balance, especially between cholesterol, triglycerides and phospholipids ${ }^{10,11}$. It was showed that with an increase of a cortisol concentration, the total cholesterol, low-density lipoprotein (LDL) and high-density lipoprotein (HDL) fraction also increases ${ }^{12}$. A similar result was presented by other authors ${ }^{13}$.

Importantly, changes in the concentration of these three lipids affect the liquidity of membranes, and, consequently, changes in the membrane transport occur ${ }^{14}$. However, other results showed, that cortisol level does not affect the lipid balance ${ }^{15}$. Sports training - especially endurance training affects the hormonal and lipid balance ${ }^{16}$. The demand for the differentiation of ingredients is very important for modern athletes ${ }^{8}$. Therefore, investigation of the correlation between cortisol level and lipid balance, and, consequently, changes in secondary structure of proteins, should be especially conducted in athletes.

Fourier-transform infrared (FTIR) and Raman spectroscopy are techniques, that provide information about chemical compositions of measured samples. Consequently, quantitative and qualitative data concerning vibrations corresponding to functional groups from phospholipids, proteins and lipids can be obtained by these techniques. In both spectroscopic techniques, two major distinct regions originating from lipid vibrations, can be identified. The high wavenumber spectral range between $2800 \mathrm{~cm}^{-1}$ and $3100 \mathrm{~cm}^{-1}$ corresponds to $\mathrm{C}-\mathrm{H}$ stretching vibrations, which mainly originates from the hydrocarbon chains, while the low wavenumber range between $1090 \mathrm{~cm}^{-1}$ and $1240 \mathrm{~cm}^{-1}$ corresponds to the $\mathrm{PO}^{2-}$ groups from phospholipids ${ }^{17,18}$. Moreover, thanks to the high sensitivity of FTIR and Raman spectroscopy, spectral signatures characteristic for each lipid class give opportunity to use these techniques to determine fine structure details. Consequently, lipid phase and orientation studies in

liposomal and monolayer systems are possible due to FTIR and Raman spectroscopy ${ }^{19,20}$. Moreover, high intensity structures in FTIR spectrum corresponding to amide I bonds provide very accurate information on the secondary structure of proteins ${ }^{21}$.

The aim of this study is to determine the structural changes in the secondary structure of proteins and in the lipid balance caused by different cortisol concentration in plasma. For this purpose, medical laboratory condition was used to obtain cortisol level results. FTIR, as well as Raman spectroscopy was applied to determine the differences in the value of absorbance and Raman intensities of individual peaks in measured spectra, corresponding to phospholipid, protein and lipid functional group. Moreover, to determine the secondary structure of proteins, fine detail of obtained FTIR was investigated.

\section{Results}

Using FTIR and Raman spectroscopy, we investigated the applicability of these technique to detect changes in the secondary structure of proteins and lipids amount, which were correlated with cortisol concentration in plasma of volleyball players. In our research we studied the differences in the value of absorbance of individual functional groups and the frequency shift of the peaks. Moreover, to determine secondary structure of proteins, we calculated second derivative of obtained FTIR spectra and we made 
deconvolution of the amide I IR region. First we analyzed all IR region, where the measurements were performed. In the Fig. 1a, characteristic FTIR peaks for phospholipid, protein and lipid vibrations in plasma, were visible. Two peaks at $1079 \mathrm{~cm}^{-1}$ and $1243 \mathrm{~cm}^{-1}$ corresponded to symmetric and asymmetric stretching vibrations of $\mathrm{PO}^{2-}$ from phospholipids, respectively. Moreover, three characteristic peaks originating from protein vibrations were noticed at $1265 \mathrm{~cm}^{-1}, 1525 \mathrm{~cm}^{-1}$ and $1654 \mathrm{~cm}^{-1}$ (amide III, amide II, amide I, respectively). Furthermore, in Fig. 1a peaks corresponded to symmetric as well as asymmetric vibrations of $\mathrm{CH}_{2}$ and $\mathrm{CH}_{3}$ groups at $2872 \mathrm{~cm}^{-1}, 2920 \mathrm{~cm}^{-1}$ and $2957 \mathrm{~cm}^{-1}$, respectively $22-$ 28. Moreover, also peaks characteristic for $\mathrm{PO}^{2-}$ from phospholipids, amide bonds and $\mathrm{CH}_{2}$ and $\mathrm{CH}_{3}$ groups from lipids, were marked in Raman spectra in Fig. 1b. The Raman shifts at $1032 \mathrm{~cm}^{-1}$ and 1240 $\mathrm{cm}^{-1}$ originated from vibrations of phosphorate groups from phospholipids ${ }^{29}$. Amide III, amide II and amide I vibrations were placed at $1266 \mathrm{~cm}^{-1}, 1544 \mathrm{~cm}^{-1}$ and $1655 \mathrm{~cm}^{-130-33}$. Symmetric as well as asymmetric vibrations of $\mathrm{CH}_{2}$ and $\mathrm{CH}_{3}$ groups were noticed between $2800 \mathrm{~cm}^{-1}$ and $2950 \mathrm{~cm}^{-134}$.

When we compared FTIR spectra presented in Fig. 1a, we noticed, that along with a decrease of cortisol concentration, the absorbance of symmetric as well as asymmetric vibrations of $\mathrm{CH}_{2}$ and $\mathrm{CH}_{3}$ lipid groups decreased. We also observed increase of absorbance of amide bonds, when the cortisol concentration in plasma decrease. The smallest differences in the absorbance were visible in IR region corresponding to phospholipid vibrations. However, we observed, that the intensity of asymmetric stretching vibrations of $\mathrm{PO}^{2-}$ was the highest in plasma of women with $12.7 \mu \mathrm{g} / \mathrm{dL}$ cortisol concentration (red spectrum). Furthermore, Raman spectra demonstrated, that the highest Raman intensity for lipid vibrations was observed for women with the highest cortisol concentration in plasma, (Fig. 1b, green spectrum). Moreover, the smallest Raman intensity for phospholipid vibrations, was visible for this spectrum. Raman spectra also presented differences in the Raman intensity and positions of peaks corresponding to amide vibrations. For women with the smallest cortisol concentration (blue and red spectra), similar Raman intensity for amide II and amide I bonds, were visible and for these vibrations the Raman shift was also similar. Interestingly, obtained spectra revealed, that along with the cortisol concentration, the shape of structures in the IR and Raman regions originating from analyzed vibrations, was changed. Consequently, to uncover more details in phospholipid, protein and lipid vibrations, second derivative of analyzed region (Figs. 2a-2d) was calculated. Moreover, to obtain information about secondary structure of proteins and calculated the percentage of alpha helix and beta sheet, second derivative of amide I bonds (Figs. 2e-2h) and deconvolution of amide I vibrations, was calculated (Figs. 2i-2l). From obtained spectra similarity in the all analyzed regions, in women with $15.2 \mu \mathrm{g} / \mathrm{dL}$ (blue spectrum) and $12.7 \mu \mathrm{g} / \mathrm{dL}$ (red spectrum), was found, (Figs. 2a-2d). In general, bands which were visible in Figs. $2 \mathrm{e}-2 \mathrm{~h}$ corresponding to $1611-1630 \mathrm{~cm}^{-1}$ were attributed as cross- $\beta$, at $1630-1644 \mathrm{~cm}^{-1}$, and $1647-1662 \mathrm{~cm}^{-1}$ as a-helix, and at $1662-1699 \mathrm{~cm}^{-1}$ as anti-parallel $\beta$-sheet ${ }^{35}$. In the Figs. $2 \mathrm{e}-2 \mathrm{~h}$, the most visible differences in the structure of protein vibrations between samples with small $(15.2 \mu \mathrm{g} / \mathrm{dL}$, $12.7 \mu \mathrm{g} / \mathrm{dL})$ and high $(19.1 \mu \mathrm{g} / \mathrm{dL}, 27.91 \mu \mathrm{g} / \mathrm{dL})$ cortisol concentration was obtained for IR region between $1665 \mathrm{~cm}^{-1}$ and $1700 \mathrm{~cm}^{-1}$, which corresponded to $\beta$-sheet secondary structure of protein. 
The deconvolution of amide I region (Figs. 2i-2l) clearly presented differences in the number of fitting curves between analysed plasma samples. However, the most important differences were visible in the number of individual secondary structure of proteins. We calculated the area of peaks corresponding to a and $\beta$ secondary structure, from which we obtained a ratio between them. For women with $27.91 \mu \mathrm{g} / \mathrm{dL}$ cortisol concentration the ratio between $\alpha$ and $\beta$ was 1.214 , for women with cortisol level $19.1 \mu \mathrm{g} / \mathrm{dL}-$ 1.227. In case of $15.2 \mu \mathrm{g} / \mathrm{dL}$ cortisol level, the $\alpha$ and $\beta$ ratio was 1.261 and for $12.7 \mu \mathrm{g} / \mathrm{dL}$ the hormone stress concentration was 1.471 .

To obtain information about differences in the number of phospholipid, protein and lipid functional groups, peak area corresponding to these vibrations was calculated and presented in Fig. 3.

Figure 3 showed differences in the peak area of peaks corresponding to phospholipid, protein and lipid vibrations in FTIR (Fig. 3a) and Raman (Fig. 3b) spectra collected from women with different cortisol concentration. Based on the FTIR data we observed, that along with the decrease of cortisol concentration the amount of lipids decreased, while the amount of proteins was increasing. Moreover, FTIR spectra presented small differences in the level of phospholipids in cortisol concentration function. While in the Raman spectra was noticed, that when cortisol concentration decreased, the area of peaks originating from phospholipids increased. Moreover, Raman spectra presented similar results when we compared cortisol concentration and protein functional groups, while in the case of peaks corresponding to lipid vibrations, we noticed amount increase along with an increase of cortisol concentration.

Table 1

Pearson correlation test between the concentration of cortisol in the plasma and the surface area of peaks originating from phospholipids, proteins and lipids, determined from FTIR and Raman spectra. $p<0,001$.

\begin{tabular}{|lllll|}
\hline \multicolumn{4}{|l}{ FTIR spectroscopy - area of peaks corresponding to functional groups from: } \\
\hline & phospholipids & proteins & lipids & cortisol concentration \\
\hline phospholipids & 1.00 & 0.95 & -0.71 & 0.70 \\
\hline proteins & 0.95 & 1.00 & -0.89 & 0.10 \\
\hline lipids & -0.71 & -0.89 & 1.00 & 0.87 \\
\hline cortisol concentration & 0.70 & 0.10 & 0.87 & 1.00 \\
\hline Raman spectroscopy - area of peaks corresponding to functional groups from: & phospholipids & proteins & lipids & cortisol concentration \\
\hline & 1.00 & 0.48 & - & -0.57 \\
\hline phospholipids & 0.48 & 1.00 & -0.80 & -0.90 \\
\hline proteins & - & -0.80 & 1.00 & 0.76 \\
\hline lipids & -0.57 & -0.90 & 0.76 & 1.00 \\
\hline cortisol concentration & & \multicolumn{3}{l}{} \\
\hline
\end{tabular}


Pearson correlation test, Table 1 presented positive, as well negative correlations between properties of analyzed samples calculated from FTIR and Raman spectra. Positive correlation means, that when amount of measured factors increases, also second factor increases, while negative correlation means, that if we notice an increase of some factor, the amount of next factor decreases. From the FTIR spectra, positive correlations between phospholipids and proteins and cortisol concentration and phospholipids, proteins and lipids, respectively, were identified. Negative correlation between lipids and phospholipids, was visible from FTIR data. Moreover, a strong negative correlation between lipids and proteins was observed in FTIR spectra. In Raman data also positive and negative correlations were obtained. Positive correlation between phospholipids and proteins and between cortisol concentration and lipids, were visible, while for cortisol concentration and proteins, as well as phospholipids, negative correlations were found. Furthermore, lack of a correlation between proteins and lipids was noticed from Raman spectra.

\section{Discussion}

In this study, two complementary optical techniques, FTIR and Raman spectroscopies were used to investigate qualitative and quantitative chemical changes in phospholipids, proteins and lipids in plasma of elite volleyball players induced by different cortisol concentration.

In both, FTIR and Raman spectra (Figs. 1a, 1b) a decrease of the absorbance and Raman intensity of peaks corresponding to $\mathrm{PO}^{2-}$ groups from phospholipid was observed when the cortisol level in plasma increased. Moreover, similar results for protein vibrations was visible in FTIR spectra, while in the Raman spectra, frequency shift corresponding to amides bonds, was noted. Figures $1 \mathrm{a}, 1 \mathrm{~b}$ and Fig. 3a, 3b showed, that with the increase of cortisol concentration, increase of $\mathrm{CH}_{2}$ and $\mathrm{CH}_{3}$ lipid vibrations were detected. Indeed, stress hormones, ex. cortisol, play a very important role in the balance between protein and lipids fraction in human body ${ }^{36}$. These hormones cause the increase of the cholesterol level simultaneously decreasing the level of phospholipids, which was observed in our FTIR spectra, Fig. 1a and Pearson correlation test, Table 1. Moreover, cortisol causes significant changes in the lipid balance, especially between phospholipid, cholesterol and triglyceride fractions. Stress can cause changes in the phospholipid structure such as shortening their carbon chain leading to the creation of a different kind phospholipid ${ }^{37}$. Furthermore, the balance between phospholipids and cholesterol plays a crucial role in the fluidity of the cell membrane and it negatively affects the structure of membrane and transport proteins $^{38}$.

Comparing the results of the plasma collected from women with different cortisol concentration, (Fig. 1b), a shift of the protein peak in the latter case towards higher wavenumbers along with the cortisol level increase, was noticed. This shift may be caused by changes in the protein molecular structure such as alterations in the amino acid composition ${ }^{37}$.

The most visible changes in the chemical structure of proteins were visible in the second derivative of the FTIR spectrum (Figs. 2d-2h) and deconvolution of structure corresponding to amide I bands (Figs. 2i-2l). It is evident, that changes in the cortisol concentration in plasma caused changes in the secondary 
structure of proteins. Cortisol affects functioning of many body organs. It is responsible for regulating the increased protein synthesis in the liver and restricts their formation in muscles and skin cells ${ }^{38}$. Moreover, cortisol stimulates the synthesis of collagen. While the cortisol content remained on a high level, the collagen synthesis was being inhibited, which could have also influenced on the secondary structure of all proteins fraction ${ }^{39}$. Moreover, cortisol is responsible also for immune system de-activation by reducing secretion of proinflammatory cytokines, which have proteins structure ${ }^{8}$.

\section{Conclusion}

Considering present results as well as the literature data, it can be stated that cortisol affects the number and structure of phospholipid, protein and lipid fraction. Results obtained from FTIR and Raman spectra well correlate with previous findings. Therefore, we think, that optical techniques could thus become effective tools for estimating the concentration of cortisol in the blood and its influence on the structure of proteins and lipid balance.

\section{Materials And Methods}

\section{Materials}

This study, all experimental protocols and methods were confirmed by the ethics committees (protocol number 3/11/2017) obtained from Institutional Review Board at Rzeszow University. All methods were carried out in accordance with relevant guidelines and regulations. Moreover, all experimental protocols were approved by Institutional Review Board at Rzeszow University committee (protocol number $3 / 11 / 2017)$. Furthermore, informed consent was obtained from all subjects.

The research was carried out on the members of one of the best professional club teams that have played for three seasons (2019-2021) of professional volleyball league in Poland and the European Cups. All 13 elite women volleyball players represented a very high sport level (1 player - the highest world level, 5 players - high international level, 3 players - the national team level, 4 - high level of league games). The number of completed training sessions was $240 \mathrm{hrs}$, the average age of the examined female players' was 27 years $+/-5$ years and 4 months. The average height of the female players' bodies was $184.61 \mathrm{~cm}+/-9.37 \mathrm{~cm}$, their average body weight was $76.27 \mathrm{~kg}+/-12.76 \mathrm{~kg}$. The average training experience of these players was 13 years and 8 months $+/-6$ years 5 months. The 10 -week pre-games workout, during which the research has been conducted, resulted in reaching the training effects as previously planned. All players improved their strength, speed, endurance and coordination indicators. No injuries that would have interrupted the players' training cycle occurred during the preparation time. After the preparatory period, all the participants improved their cardiovascular and respiratory parameters maximal oxygen consumption (VO2) max. There was an increase in the mean values of VO2 in the group of female competitors from $41,40 \mathrm{ml} / \mathrm{kg} / \mathrm{min}$ to $45,18 \mathrm{ml} / \mathrm{kg} / \mathrm{min}$. Changes in the body composition parameters that were discovered after the analyzed preparatory training period included a decrease in fat 
mass and an increase in muscle mass with slight changes in body weight. From each study participant, 5 $\mathrm{mL}$ of whole blood was drawn into an EDTA tube.

\section{Collection and processing of blood samples}

A total number of 49 samples was collected (four times - during a 10 - weeks training cycle) in the mornings (from 7:00 to 8:30 AM) from the athletes (who had been without any breakfast), in the preparation for their next league season. The intervals between samples collection were set at 3 weeks. Blood samples were processed at the Centre for Innovative Research in Medical and Natural Sciences on the same day they had been collected. The samples were first centrifuged at $1000 \times \mathrm{g}$ at $4^{\circ} \mathrm{C}$ for 5 minutes in the collection tube and next, plasma was removed and stored at $-80^{\circ} \mathrm{C}$ until further analysis.

\section{Consent for study participation}

Consent for participation in a research experiment

First name:

Surname:

I give my consent and take a conscious part in a research experiment carried out as part of scientific research at the University of Rzeszów :

"Variability of blood biochemical parameters in the preparatory period of elite sports players".

Signature:

\section{Methods}

\section{Spectroscopic techniques}

Directly before the analysis, all plasma samples were thawed and subsequently measured by Raman and FTIR spectroscopies. The samples were vortexed for $20 \mathrm{sec}$ prior to the measurement and the plasma was collected from the bottom of the tube. All measurements were performed in triplicates according to the following procedure. For each sample, the same volume of plasma was obtained. Thus, from 3x49 measurements 147 spectra were collected. Next, the 3 spectra from each sample were averaged using OPUS software.

The spectroscopy measurement parameters and samples preparation, were described previously in work Depciuch et al. ${ }^{40}$

\section{Raman spectroscopy}

The plasma samples were measured using a SmartRaman DXR spectroscope (Thermo Scientific, USA) with the $780 \mathrm{~nm}$ light source wavelength. The spot size was $5 \times 5 \mathrm{~mm}$, while the laser power - $14 \mathrm{~mW}$. 
Furthermore, the light source was heated around 5 minutes before measurement. In this study, we used $1,5 \mathrm{ml}$ od plasma, which were measured using special tubes. All obtained Raman spectra were normalized using vector normalization. Moreover, baseline correction was performed ${ }^{40}$.

\section{FTIR spectroscopy}

In this study we used Vertex 70 spectrometer to obtain FTIR spectra of plasma. Attenuated Total Reflectance (ATR) technique, was used, where the ATR had a diamond crystal. Moreover, after measured, these diamond crystal was cleaned using ethanol. The measurements were done in all IR average region $\left(400 \mathrm{~cm}^{-1}-4000 \mathrm{~cm}^{-1}\right)$. Each sample was scanned 64 times using $2 \mathrm{~cm}^{-1}$ spectral resolution. Moreover, before each sample measurement, the background (water sample), which automatically was subtracted from the sample spectrum, was collected. We used water, because plasma samples had around $99 \%$ of $\mathrm{OH}$ molecules. All obtained spectra were analyzed using OPUS 7.0 software, where baseline correction and normalization was applied ${ }^{40}$.

\section{Data analysis of primary amide region $\left(1600 \mathrm{~cm}^{-1}-1700\right.$ $\mathrm{cm}^{-1}$ )}

To determine secondary structure of protein, GRAMS Al software (Thermo Scientific), was used. Moreover, the positions of curve fittings, was obtained from the secondary derivative of FTIR spectra, which were calculated using OPUS 7.0 software. Next, a straight baseline passing through the ordinate at $1610 \mathrm{~cm}^{-1}$ and $1700 \mathrm{~cm}^{-1}$ was subtracted and modified by the least-squares curve fitting program. In this study we used Gauss curve to obtain the best fitting. To obtain information about secondary structure of proteins, the area of peas corresponding to a-helix and $\beta$-harmonica, were calculated using the ORIGIN software and next ratio between these two secondary structure, was obtained.

\section{Statistical analysis}

The sum of peaks area, which was originating from phospholipid, lipids and proteins functional groups, was presented as means \pm SEM (the standard error of the mean). Moreover, for this purpose, one-way ANOVA followed by the Tukey's test was performed. To determine negative and positive correlation between phospholipids, lipids, proteins vibrations and cortisol concentration, the Pearson's test with the $p$ $<0.001$ value was calculated using Past 3.0 software $^{40}$.

\section{Declarations}

\section{Author Contributions}

Conceptualization, J.D and W.Cz.; Methodology, J.D., W.B, A.P., I.t-S.; Validation, J.D. and B.K.; Formal Analysis, J.D., Writing-Original Draft Preparation, J.D. and W.Cz.; Writing-Review and Editing, A.R. and W.Sz.; Visualization, J.D.; Supervision, J.C. and P.K.. All authors have read and agreed to the published version of the manuscript. 


\section{Funding}

Financial support from the College of Medical Sciences Institute of Physical Culture Studies University of Rzeszow ul Towarnickiego 3, 35-959 Rzeszów Poland, grant WWF/PB/6 "Research in the assessment of the impact of sports training on the human body" is acknowledged.

\section{Competing interests}

The authors declare no conflict of interest.

\section{References}

1. Martinovic, J. et al. Long-term effects of oxidative stress in volleyball players. Int. J. Sports Med.30, 851-856 (2009).

2. Filaire, E., Duche, P. \& Lac, G. Effects of amount of training on the saliva concentration of cortisol, dehydroepiandrosterone and on the dehydroerpiandrosterone: cortisol concentration ratio in women over 16 weeks of training. Eur. J. Appl. Physiol. Occup. Physiol.78, 466-471 (1998).

3. Edwards, D. A. \& Casto, K. L. Women's intercollegiate athletic competition: cortisol, testosterone, and the dual-hormone hypothesis as it relates to status among teammates. Horm. Behav.64, 153-160 (2013).

4. Roli, L. et al. Testosterone, cortisol, hGH, and IFH-1 levels in an Italian female elite volleyball team. Health Sci. Rep.1, e32 (2018).

5. Dziembowska, J. et al. Female volleyball players are more prone to cortisol anticipatory stress reposnse than sedentary women. Medicina (Kaunas).55, 258 (2019).

6. Crewther, B. T., Cook, C., Cardinale, M., Weatherby, R. P. \& Lowe, T. Two emerging concepts for elite athletes: the short-term effects of testosterone and cortisol on the neuromuscular system and the dose-response training role of these endogenous hormones. Sports Med.41, 103-123 (2011).

7. Cupps, T. R. \& Fauci, A. S. Corticosteroid-mediated immunoregulation in man. Immunol. Rev.65, 133155 (1982).

8. Stachowicz, M. \& Lebiedzińska, A. The effect of diet components on the level of cortisol. Eur. Food Res. Technol.242, 2001-2009 (2016).

9. Heinrichs, S. C. \& De Souza, E. B. Corticontropin-releasing factor antagonists, binding - protein and receptors: implication for central nervous system disorders. Baillieras Best Pract. Res. Clin. Endocrinol. Metab.13, 541-554 (1999).

10. Sashin, E. \& Humuslu, S. Alternations in brain antioxidant status, protein oxidation and lipid peroxidation in response to different stress models. Behav. Brain Res.155, 241-248 (2004).

11. Breen, K. M. et al. Insight into the neuroendocrine site and cellular mechanism by which cortisol suppresses pituitary responsiveness to gonadotropin-releasing hormone. Endocrinology.149, 767773 (2008). 
12. Maduka, I. C., Neboh, E. E. \& Ufelle, S. A. The relationship between serum cortisol, andrenaline, blood glucose and lipid profile of undergraduate students under examination stress. Afr. Health. Sci.15, 131-136 (2015).

13. Misra, M. et al. Lower growth hormone and higher cortisol are associated with greater visceral adiposity, intramyocellular lipids, and insulin resistance in overweight girls. Am. J. Physiol. Endricnol. Metab.295, E385-E392 (2008).

14. Maes, M., Smith, R. \& Scharpe, S. The monocyte-T-lymphocyte hypothesis of major depression. Psychoneuroendocrinol.20, 111-116 (1995).

15. Christiansen, J. J. et al. Effects of cortisol on carbohydrate, lipid, and protein metabolism: studies of acute cortisol withdrawal in adrenocortical failure. J. Clin. Endocrinol. Metab.92, 3553-3559 (2007).

16. Fikenzer, K., Fikenzer, S., Laufs, U. \& Werner, C. Effects of endurance training on serum lipids. Vascul. Pharmacol.101, 9-20 (2018).

17. Derenne, A., Vandersleyen, O. \& Goormaghtigh, E. Lipid quantification method using FTIR spectroscopy applied on cancer cell extracts. Biochim. Biophys. Acta.1841, 1200-1209 (2014).

18. Czamara, K. et al. Raman spectroscopy of lipids: a review. J. Raman Spectrosc.46, 4-20 (2015).

19. Derenne, A., Claessens, T., Conus, C. \& Goormaghtigh, E. Infrared spectroscopy of membrane lipids in Encyclopedia of Biophysics (ed. Roberts, G. C. K.) 1074-1081(Springer, 2013).

20. Wolkers, W. F. Biomedical FTIR spectroscopy of lipids in Biological and Biomedical Infrared Spectroscopy (ed. Barth, A., Haris, P. I.) 272-287(IOS Press, 2009).

21. Arunkumar, R., Drummond, C. J. \& Greves, T. L. FTIR spectroscopic study of the secondary structure of globular proteins in aqueous protic ionic liquids. Front. Chem.7, 74 (2019).

22. Hands, J. R. et al. Attenuated total reflection Fourier transform infrared (ATR-FTIR) spectral discrimination of brain tumour severity from serum samples. J. Biophotonics.7, 189-199 (2014).

23. Bonnier, F., Petitjean, F., Baker, M. J. \& Byrne, H. J. Improved protocols for vibrational spectroscopic analysis of body fluids. J. Biophotonics.7, 167-179 (2014).

24. Merrell, K. et al. Analyss of low-abundance, low-molecular-weight serum proteins using mass spectrometry. J. Biomol. Tech.15, 238-248 (2004).

25. Roche, S. et al. Depletion of one, six, twelve or twenty major blood proteins before proteomic analysis: the more the better? J. Proteomics.72, 945-951 (2009).

26. Finoulst, I., Pinkse, M., Dongen, W. V. \& Verhaert, P. Sample preparation techniques for the untargeted LC-MS-based discovery of peptides in complex biological matrices. J. Biomed. Biotechnol. 2009, 245291 (2009).

27. Petrich, W. et al. Potential of mid-infrared spectroscopy to aid the triage of pateints with chest pain. Analyst.134, 1092-1098 (2009).

28. Hughes, C. et al. Assessing the challenges of Fourier transform infrared spectroscopic analysis of blood serum. J. Biophotonics.7, 180-188 (2014). 
29. Cheng, W-T., Liu, M-T., Liu, H-N. \& Lin, S-Y. Micro-Raman spectroscopy used to identify and grade human skin pilomatrixoma. Microsc. Res. Tech.68, 75-79 (2005).

30. Dukor, R. K. Vibrational spectroscopy in the detection of cancer in Handbook of Vibrational Spectroscopy (Chalmers, J. M. \& Griffiths, P. R.) 3335-3359 (John Wiley \& Sons, 2006).

31. Huang, Z. et al. Near-infrared Raman spectroscopy for optical diagnosis of lung cancer. Int. J. Cancer.107, 1047-1052 (2003).

32. Stone, N., Kendall, C., Smith, J., Crow, P. \& Barr, H. Raman spectroscopy for identification of epithelial cancers. Faraday Discuss.126, 141-157 (2004).

33. Stone, N., Kendall, C., Shepherd, N., Crow, P. \& Barr, H. Near-infrared Raman spectroscopy for the classification of epithelial pre-cancers and cancers. J. Raman Spectrosc.33, 563-573 (2002).

34. Kline, N. J. \& Treado, P. J. Raman chemical imaging of breast tissue. J. Raman Spectrosc.28, 119124 (1997).

35. Bhatia, N. K. et al. Curcumin binds to the pre-fibrillar aggregates of $\mathrm{Cu} / \mathrm{Zn}$ superoxide dismutase (SOD1) and alters its amyloidogenic pathway resulting in reduced cytotoxicity. Biochim. Biophys. Acta.1854, 426-436 (2015).

36. Acconcia, F. \& Marino, M. Steroid hormones: synthesis, secretion, and transport in Principles of Endocrinology and Hormone Action. Endocrinology (Belfiore, A. \& LeRoith, D.) (Springer, 2016).

37. Roy, A. S., Tripathy, D. R., Chatterjee, A. \& Dasgupta, S. A spectroscopic study of the interaction of the antioxidant naringin with bovine serum albumin. J. Biophys. Chem.1, 141-152 (2010).

38. Larsen, R. \& AnestezjologiaEdra Urban \& Partner, 2013.

39. Papierska, L., Rabijewski, M. \& Misirowski, W. Glucocortycoid-incucted osteoporosis. Prog. Med.6, 389-393 (2008).

40. Depciuch, J. et al. Qualitative and quantitative changes in phospholipids and proteins investigated by spectroscopic techniques in animal depression model. Spectrochimica Acta Part A: Molecular and Biomolecular Spectroscopy.176, 30-37 (2017).

\section{Figures}



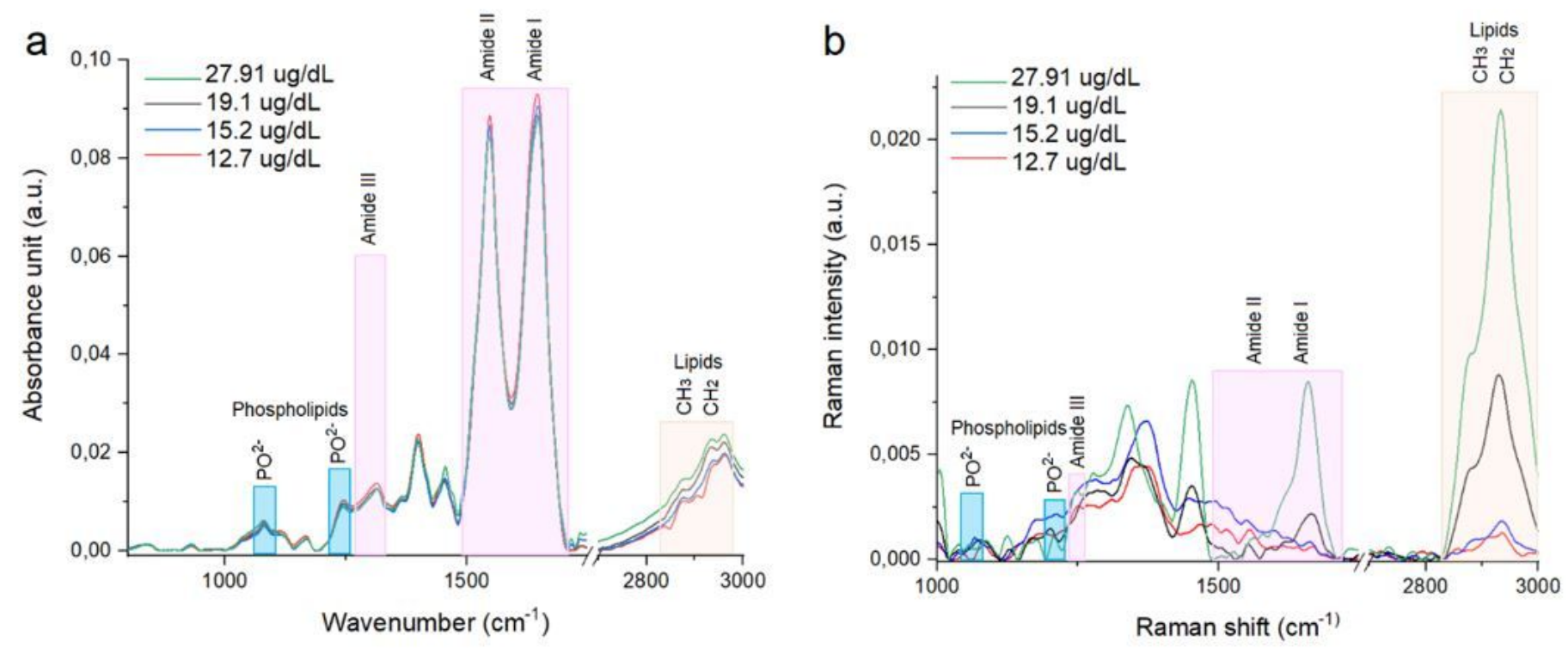

Figure 1

FTIR (a) and Raman (b) spectra of plasma collected from women with various cortisol concentrations: $27.91 \mu \mathrm{g} / \mathrm{dL}$ (green spectra); $19.1 \mu \mathrm{g} / \mathrm{dL}$ (black spectra), $15.2 \mu \mathrm{g} / \mathrm{dL}$ (blue spectra) and $12.7 \mu \mathrm{g} / \mathrm{dL}$ (red spectra).

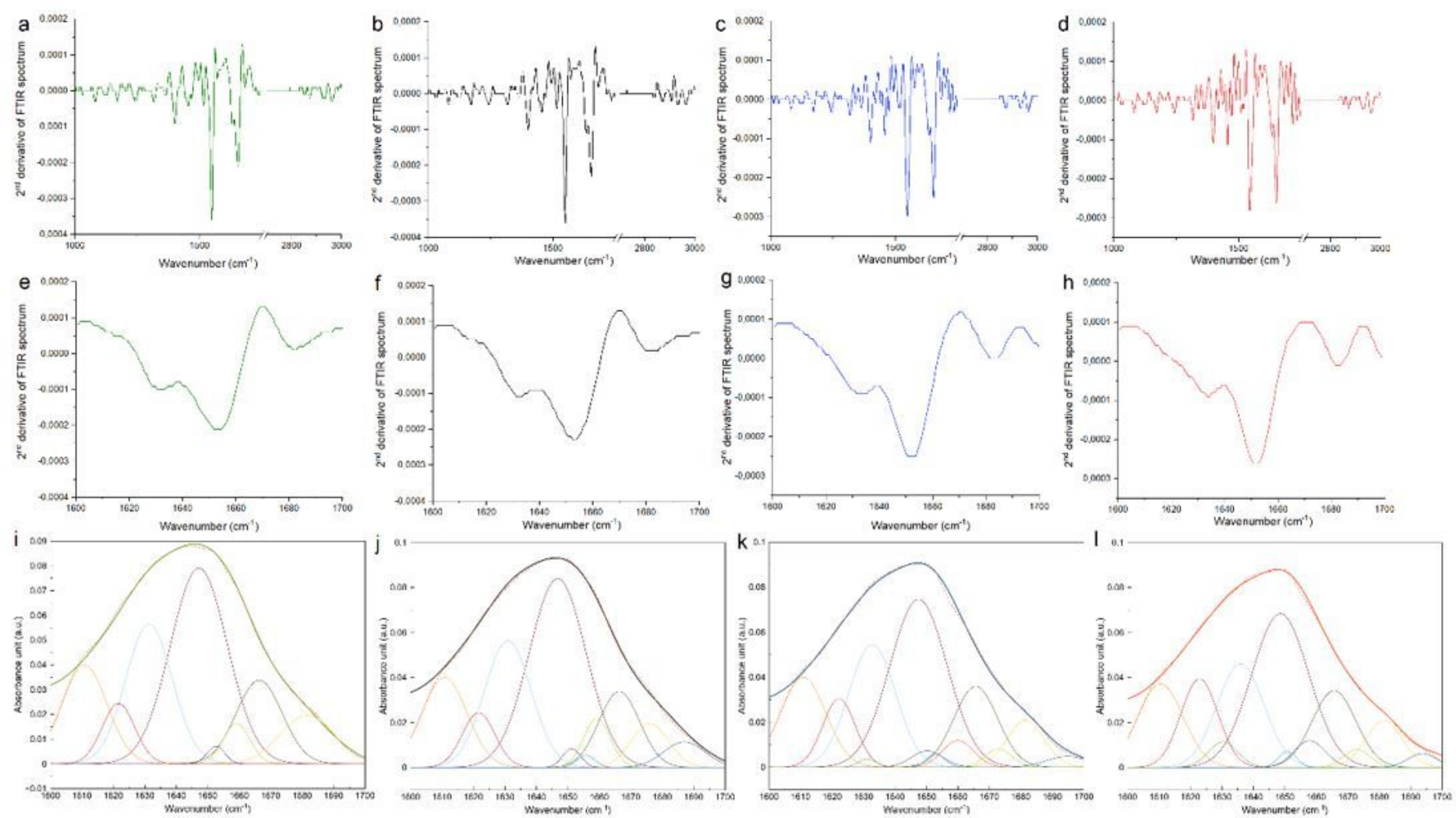

Figure 2 
Second derivative of FTIR spectra taken at various regions: between $1000 \mathrm{~cm}-1$ and $1700 \mathrm{~cm}-1$ and between $2700 \mathrm{~cm}-1$ and $3000 \mathrm{~cm}-1$ (a-d); amide I vibrations (e-h) and deconvolution of amide I bands (i-I) of plasma collected from women with different cortisol concentration: $27.91 \mu \mathrm{g} / \mathrm{dL}$ (green curves), 19.1 $\mu \mathrm{g} / \mathrm{dL}$ (black curves), $15.2 \mu \mathrm{g} / \mathrm{dL}$ (blue curves) and $12.7 \mu \mathrm{g} / \mathrm{dL}$ (red spectra).
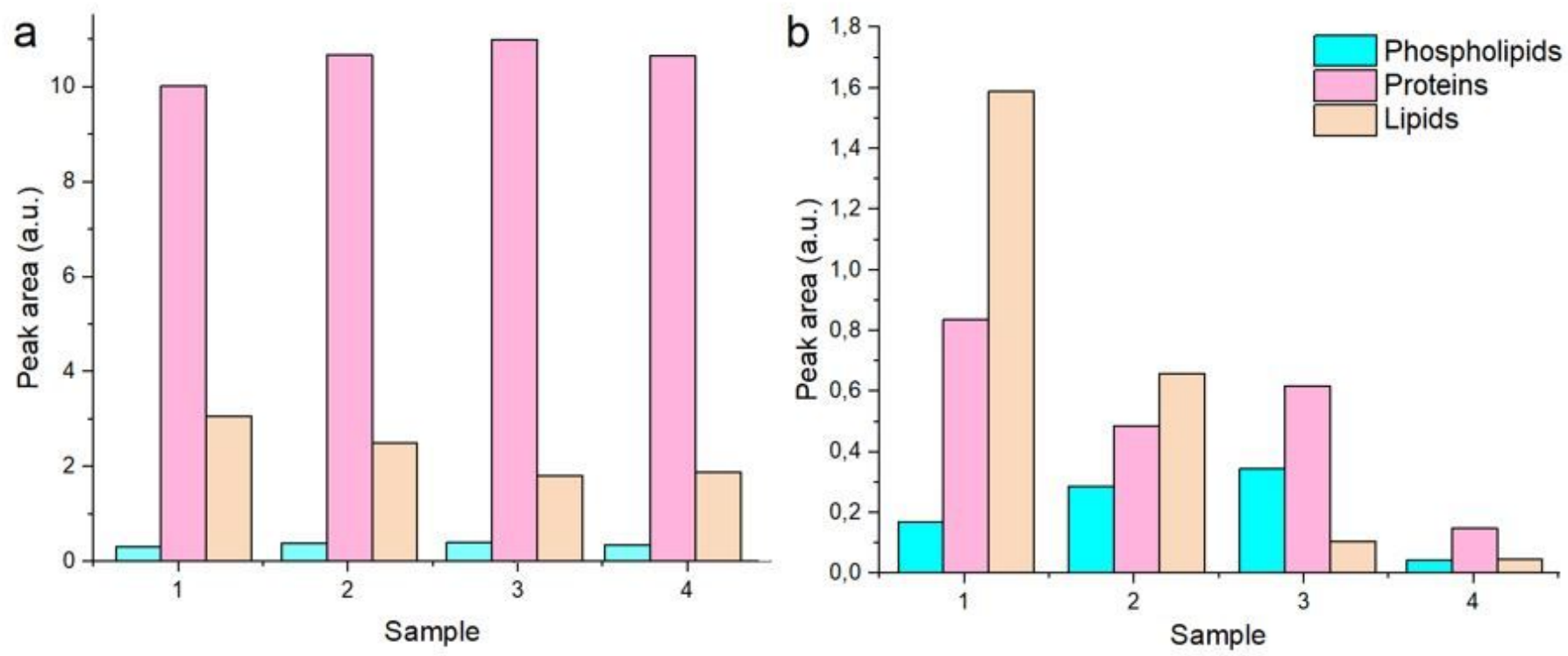

\section{Figure 3}

The values represent the intensity of peaks measured by a FTIR (a) and Raman (b) spectroscopy for selected wavenumbers range corresponding to phospholipids (blues), protein (pink) and lipids (orange). All the measurements for each group were performed in triplicates. Resulting data were analyzed by oneway ANOVA followed by Tukey's post hoc test. The number 1 means cortisol concentration from 27 $\mu \mathrm{g} / \mathrm{dL}$ to $30 \mu \mathrm{g} / \mathrm{dL}, 2$ - between $17 \mu \mathrm{g} / \mathrm{dL}$ and $19 \mu \mathrm{g} / \mathrm{dL}, 3$ - between $14 \mu \mathrm{g} / \mathrm{dL}$ and $16 \mu \mathrm{g} / \mathrm{dL}$ and $4-$ between $10 \mu \mathrm{g} / \mathrm{dL}$ and $13 \mu \mathrm{g} / \mathrm{dL}$. 